\title{
What Would Humboldt Say: A Case of General Bildung in Vocational Education?
}

\author{
Ruhi Tyson* \\ Stockholm University, Department of Education, 10691 Stockholm, Sweden
}

Received: 08.03.2016; Accepted: 07.09.2016; Published: 19.12.2016

\begin{abstract}
A classic philosopher in the Bildung-tradition, Humboldt, argued that general Bildung was the opposite of specialist training (vocational education). This has been a matter of contention and the aim here is to revisit the issue through an empirical case study. In the vocational education biography of craft master Wolfgang B. he speaks about aspects of his education that have much in common with Humboldt's ideal of general Bildung but transposed into the context of vocational education and training (VET). The concept of vocationalism (Beruflichkeit) provides context to the present argument which is that the contrast Humboldt made is relevant but not in the sense of there being two categories of education (general and vocational) but rather two expressions of pedagogy: one expansive and one exclusive. Furthermore, there are two versions of general or expansive Bildung present in the case. The conclusions are that empirical studies of vocational Bildung expand on the concept of Bildung, increase our understanding of how VET contains affordances of Bildung and of the curriculum-patterns related to this.
\end{abstract}

Keywords: Vocational School, Instructional Design, Curriculum Development, Case Study, Educational Innovation, Vocational Education and Training

\footnotetext{
*Corresponding author: ruhi.tyson@edu.su.se
}

ISSN: $2197-8646$

http://www.ijrvet.net 


\section{Introduction}

Debates about the contents and structure of vocational education and training (VET) have been going on for several centuries. From a pedagogical perspective the fact that VET is oriented towards specialized work and socio-economic benefit has led many prominent educational philosophers to outright discount VET as education. A famous example is Plato who remarks in the dialogue Laws (Plato, 2008):

At present, when we speak in terms of praise or blame about the bringing-up of each person, we call one man educated and another uneducated, although the uneducated man may be sometimes very well educated for the calling of a retail trader, or of a captain of a ship, and the like. For we are not speaking of education in this narrower sense, but of that other education in virtue from youth upwards, which makes a man eagerly pursue the ideal perfection of citizenship, and teaches him how rightly to rule and how to obey. This is the only education which, upon our view, deserves the name; that other sort of training, which aims at the acquisition of wealth or bodily strength, or mere cleverness apart from intelligence and justice, is mean and illiberal [the Swedish translation (2008) has slavelike here and the German (quoted in Lange et al., 2001, 195) craftsmanlike], and is not worthy to be called education [the German translation (ibid., 2001, 195) has Bildung here] at all.

Similarly, the German educational reformer Wilhelm von Humboldt (1767-1835) distinguished between special (vocational) and general Bildung. Bildung used here in the sense of education in general but also the formation of character, development of autonomy, etc. (cf. Lüth, 1998) for a treatment of Humboldt's Bildung-philosophy). This distinction by Humboldt is still part of the current debate in Germany (eg. Kutscha, 2003; Lange et al., 2001; Reutter, 2004) and the kind of dichotomizing described has not been without its critics. In Germany, reformers such as Kerschensteiner argued for (based in part on Dewey), and implemented, the inclusion of vocational tasks in the general curriculum (Gonon, 2002; Kerschensteiner, 1904; Lange et al., 2001). Furthermore, Bildung as part of vocations and vocational education has been discussed extensively and sometimes in connection with what is called vocationalism (Beruflichkeit) given that the construction of a vocation and the education preparing for it determines much of its Bildung-potential (eg. Brater et al., 1988; Gessler and Howe, 2015; Kutscha, 2003, 2008; Obermann, 2013; Rauner and Bremer, 2004; Rist and Schneider, 1979). Outside of the German context similar arguments have been advanced, not least by Dewey (Løvlie and Standish, 2002, 321f.) and more recently from sociological and philosophical perspectives in eg. Sennett (2008), Crawford (2009), Dormer (1994), Frayling (2011), Volanen (2012) and With (1994). Thus from a theoretical perspective the kind of sweeping distinction Plato made is seldom defended. However, as Biesta writes in a discussion on general Bildung $(2002,389$, italics in original): 'the crucial point [...] is to show that things can be different.' The aim here is not foremost to revisit the theoretical discussion but rather to suggest an empirical approach to the largely philosophical argument. This is developed through a case study of the vocational education biography of craftmaster 
Wolfgang B. (presented in full in Tyson 2015a).

The research aim of the inquiry is twofold: first to discuss, question and expand upon the concept of vocational or special Bildung as it relates to general Bildung and vocationalism, thereby laying a foundation for how cases such as the one presented can be interpreted; second to consider the curriculum patterns suggested by the case and the potential inherent in further, comparative, studies. To this can be added a more practical aim, to contribute to the published repertoire of cases. The resulting conclusions, beyond the conceptual work presented, are:

1. That this Humboldt-related interpretation provides a way of empirically examining relations between generalist and specialist curricula and allows for systematic analysis across multiple cases regarding patterns in vocational Bildung-affordances that are difficult to achieve with other means.

2. The discussion regarding how to construct VET curricula, what vocational training does and especially what it can contribute needs more empirically grounded cases (Biesta's showing how things can be different).

3. This case and cases like it can be direct contributions to the practical imagination of those constructing vocational curricula or teaching vocational skills.

The argument will begin with a discussion of why Bildung is a relevant concept in research on VET given the various critical perspectives that have been advanced (eg. Løvlie and Standish, 2002 (who summarize Adorno's classic critique); Masschelein and Ricken, 2003; Thompson, 2005) situating it within a framework of vocationalism (Beruflichkeit). From this it will move to a conceptual discussion of Bildung and Humboldt in order to advance a view on how his theoretical perspective can be made fruitful in the interaction with, as well as interpretation of, the case study. Before moving on to the case, questions of methods and research design are dealt with after which relevant parts of the case of the vocational education biography of Mr. Wolfgang B. are presented. The article ends with a discussion and a conclusion.

\section{Bildung in the framework of vocationalism and as an empirically relevant concept}

Introducing the concept of vocational Bildung warrants some justification. Why isn't it enough to think of and enact VET as a fairly instrumental form of training? And what does Bildung contribute to empirical research? Rather than to reiterate arguments made by others and myself about human flourishing in work, the need to promote it and its overlap with processes of Bildung (eg. Hinchliffe, 2004; Lazlo et al., 2012; Tyson, 2015a), as well as the similarity between the processes and contents of Bildung and those of some iterations of so-called key-qualifications I will deal with the questions differently here. Already since at least the 1930s it has been questioned if the issue of vocational education for specific vocations (German: Berufe) is not becoming outdated owing to the 
increased flexibility and mobility of work (eg. Gruschka, 2011; Kutscha, 2008; Winch, 2012). Kutscha (2008, 7, my translation) writes:

This suggests the conclusion that we give up all forms of vocationalism ${ }^{1}$ (German 'Beruflichkeit') corresponding to the 'victory of the Animal laborans' over culture as the 'Condition humaine' (Arendt, 1989, 14 and 312). If one is not eager to encourage such a scenario then the connections between work and vocation, Bildung and culture demand greater attention. This is the conceptual matrix that a theory of vocational Bildung has to relate to if it is to make any claim to do justice to both the vocationalism of the acting subject and the employment system [...].

I agree and the present work is an empirical inquiry into the conceptual matrix of work and vocation, Bildung and culture using a development of Humboldt's ideas as historical context. The point with such empirical inquiries even into comparatively peripheral vocations such as crafts is that they have a potential to provide a foundation for some of the arguments otherwise mostly made on a theoretical/philosophical level. Thus in a more basic sense the present inquiry is an argument that if we do not wish to encourage what Arendt worried about as the 'victory of the Animal laborans' then we need not only to think differently but we also need to recognize those elements of already enacted social practice where this has, in one way or other, been achieved (however limited these achievements are). There are several reasons for this, one being that the accumulation of such cases is part of the argument against getting rid of vocationalism in VET and work. The reason I would like to highlight here, because I have not seen it referred to in the literature on VET, is that a theory of vocational Bildung cannot tell us much about how to move from the generality of theory into the particularity of practice. This enactment of theory or conceptual framework requires the work of interpretation or imagination because there is almost never a singular and obvious way of doing things. I have argued for this elsewhere (Tyson, 2016a), drawing on Schön $(1983,1987)$ as the use of pedagogical imagination. According to this a case can become part of a practitioners ${ }^{6}$ repertoire enriching their capacity to recognize further situations as similar cases and their ability to draw on that previous knowledge in order to imagine ways in which to approach the present situation. Viewed from this perspective the documentation of cases of vocational Bildung provides us with content for our pedagogical imagination when we aim at understanding how vocational Bildung as theory can be enacted in practice and how this enactment contributes to the enrichment of theory and to the development of curricula (as a pattern or template). What is proposed here then is that unusually rich biographical cases have something to say on a more concrete level, the case of Wolfgang B. regarding a craft education. What similar educational biographies would yield in

\footnotetext{
${ }^{1}$ This is clearly a somewhat polemical statement given that there are many fields of work where vocationalism is still comparatively relevant such as medicine, education, and many crafts. However the issue is one of VET policy given that many fields of work can be made more or less vocational and it needs to be recognized that this is both an economic and educational question. There are few facts to lean on and mostly matters of achieving consensus on what is most desirable when balancing questions of work, economy, education and Bildung.
} 
other fields, such as medicine, architecture, engineering, etc. remains to be seen. It is also of importance to inquire empirically into how the tension between instrumental and Bildung-oriented education has been solved successfully pedagogically (again, Biesta's showing). From the point of view advanced here, it is not meaningful to imagine a solution in either of the extremes. Purely instrumental VET that seeks to efficiently train skills and nothing more forgets that the continuously asked for key-qualifications, capacity for self-regulated biographical development and lifelong learning capability can all be viewed as Bildung-related issues that suffer when little or no attention is paid to personal context, interest, etc. Likewise, a complete focus on Bildung disregarding any instrumental orientation towards the world can only lead to solipsism, at least in a VET context. A person unfolds her or his biography in a social context where work tends to play an important role, and here a certain instrumental and impersonal aspect cannot be avoided. It is the tension that is interesting and that requires a pedagogicaldidactical stance. This is also a contributing reason for why empirical Bildung-studies are relevant. Because this tension has to be solved in practice and can only be pointed to in theory/philosophy. Having thus proceeded to elaborate on the initial questions about vocational Bildung and the aims of the inquiry I will now turn to the central conceptual matter, Bildung and Humboldt.

\section{Bildung and Humboldt}

Bildung is an educational concept with many roots. Thus Rittelmeyer (2012) identifies one tradition that reaches back to antiquity and the classical ideal expressed by Plato in the introductory quote and here it shares roots with the tradition of liberal education. He finds another one connected to the medieval religious ideal as articulated by, among others, the mystic Eckhart of becoming an image of God (Bildung literally means formation or making into an image). Finally Bildung also has strong roots in the German Enlightenment and early Romantic period in the thought of Kant, Humboldt, Goethe, Schiller, Novalis, Schelling and many more. The concept encompasses matters such as moral formation, aesthetic sensibility, autonomy, wide ranging generalist knowledge and, importantly for empirical research, all in connection with biographical developments (to confuse the matter Bildung is also used in the same general sense as education in English giving many texts a curious ambivalence). Thus experiences of Bildung are, to a large extent, equivalent to those experiences that in retrospect are deemed to have enriched one's life significantly and memorably. This does not exclude Bildung as an experience that is more embodied and tacit nor does it ignore the many issues that are connected with remembering events in one's life that happened long ago. But the point is that asking a person about educational experiences that were especially memorable and enriching for the most part results in answers that fit in the tradition of Bildung taken in its broader sense (Tyson, 2015a). The biographical perspective and its connection to the possibility of empirical study is seldom emphasized in philosophical writing on Bildung (eg. Hammershøj, 2009; Løvlie, 2002; Løvlie and Standish, 2002; Nordenbo, 2002). However it is precisely in such inquiry that we can move from a repetitive back 
and forth on questions of Bildung-theory into practical considerations of how actual Bildung-affordances have been experienced and their potential for research and action. Returning to the concept of Bildung, from the above it is clear that Allgemeinbildung (general Bildung) ${ }^{2}$ has been an ideal of comprehensive education for far longer than the 200 years since Humboldt. In his restatement of the various aims of Bildung he contrasts them with VET perhaps most distinctly in the Lithuanian school-plan (1984, 76-82, my translations):

All schools [...] have to support only the development of general human Bildung [allgemeine Menschenbildung]. That which concerns the basic needs of life or the expertise of some individual in his vocation has to be removed and to take place after the completion of general studies. If they are mixed, Bildung becomes impure and one achieves neither complete human beings nor complete citizens. [...] Through general Bildung it is the [...] human being as such that is to be strengthened, refined and regulated. Through special Bildung it is only skills/competences for use that are developed.

To be clear, Humboldt made his distinction in order to argue for a school system with late selection, ie. a system where education was initially general for all and only later became specialized and vocational. To do Humboldt justice it is perhaps reasonable to ignore his focus on classical languages, mathematics and ancient history as the subjects of general Bildung and to think of his general and special Bildung as two expressions of pedagogy: one expansive and one exclusive or intensive. His argument then is that exclusive educational aims need to follow and build on expansive ones (in effect that breadth precedes depth). This makes it less dichotomizing since it is possible to consider any number of positions between extremely expansive and extremely intensive (even if Humboldt seems to say that any mixing makes both impure, something the case contradicts). This expansive-exclusive/intensive tension is the conceptual lens through which I will be viewing the case. Thus the conceptual framework for interpreting cases such as this rests on a foundation of vocational Bildung and vocationalism together with this more specific concern with how elements of an expansive pedagogy and curriculum can be found in what is otherwise thought of as primarily an exclusive or intensive vocational education. To be clear, this Humboldt-related perspective is part of a wider framework where eg. aesthetic Bildung represents another way of interpreting this and other cases (Tyson, 2014). I will return in the case presentation and in the ensuing discussion to how the particular concern with an expansive pedagogy and curriculum relate to matters of vocationalism. Before I go on to present the case something needs to be said about the theory, research design and methods involved in researching such cases.

\footnotetext{
${ }^{2}$ German readers, or readers familiar with the German Bildung-theoretical discourse as well as the empirical research in the field, will perhaps find this section on Humboldt both somewhat superficial and basic. However, much of this is not available in other languages (exceptions are Gonon, 2009; Lüth, 1998; Westbury et al., 2000). There seems to be no full translation of Humboldt's educational texts into English even though Lüth compares Humboldt's influence in German educational thought to that of Dewey's in the US $(1998,43)$.
} 


\section{Theory, research design and methodology}

This inquiry is part of a larger study (Tyson, 2015a, 2016a, b, c) into the theory and practice of what I have tentatively called vocational Bildung didactics. Having already considered vocational Bildung I turn to the understanding of didactics that underpins the case study design. Didactics, as understood here, encompasses the what, why, how, to whom and when of teaching together with the way this is organized in curricula (eg. Uljens, 2004). Furthermore, and centrally, it is understood here from a practical perspective, i.e. as a craft-like form of knowledge requiring extensive practice in addition to study for the development of proficiency. In contrast to an actual craft however, Bildung-didactical knowledge is not available to observation the way a craftsperson can access previous work and learn from it. Thus unless this knowledge is somehow articulated it remains tacit and difficult both to learn and to conduct systematic comparative research into. Case studies represent a way of expressing such knowledge and making it public. This can be cases of teachers telling stories of enacted Bildung-affordances or, as in the present one, of students/apprentices and their Bildung-related experiences of teachers and curricula.

To avoid confusion a further distinction can also be made between subject-didactical and Bildung-didactical practical knowledge. The subject-didactical knowledge, eg. teaching mathematics or engine repair, can be accessed through narratives but also through observation making it open to research through video recording and participant observation. Bildung-didactical knowledge is different. As previously stated it includes ethics, character development, a sense of autonomy and, central to the present context, a coherent, personalized sense of expansive knowledge including an experience of vocationalism as Kutscha writes. All of these matters are difficult or impossible to observe, they mostly need to be narratively expressed and they also tend to occur infrequently, become apparent only in retrospect and to resist pedagogical planning. At best, Bildung can be afforded by a teacher to a student/apprentice, never guaranteed. This has two consequences. First that Bildung didactics as a form of practical knowledge is fragmentary even among experienced teachers given that practice is limited and tacit and unless they happen to work in a context where vocational Bildung is explicitly supported and where there is an established practice of sharing relevant case narratives it is also highly personal. Second we have almost no systematically articulated knowledge of Bildung didactics because we lack the requisite cases. What we have are abstractions and rules of thumb by experienced practitioners but it is important not to confuse propositional theory with concrete practice. As stated in part two, the enactment of theory or conceptual framework, ie. the enactment of Bildung didactics, requires the work of interpretation or imagination because there is almost never a singular and obvious way of doing things. This makes the concept of pedagogical imagination central to the framework (Tyson 2016a) where, beyond what was stated previously, following Schön (1987), it is understood that a skilled teacher has developed a repertoire of articulate and tacit examples through which s/he re-interprets/re-imagines a new situation. Thus each narrative case holds didactical knowledge to the degree that it can contribute in a multitude of ways to the didactical/pedagogical imagination of practitioners and scholars. A further dis- 
cussion of these different contributions is presented in Tyson (2016b) where five general kinds are considered: enriching knowledge of vocational tasks; conceptual development and critical reflection; advancement of practice; development of practice fields and the articulation of patterns of vocational Bildung-affordances.

The combination of these elements is developed within the broader theoretical framework of phronetic social science (Flyvbjerg, 2001; Flyvbjerg et al., 2012). This framework is concerned less with the generation of theory than with the improvement of practice especially those aspects related to it that concern wise practices (phronesis). This aligns well with a focus on Bildung from a didactical point of view.

The design of case studies in this field is flexible in that the narratives can be gathered through interviews and through writing assignments depending on circumstances and on specific aims. Interviews generally allow for a more focused selection of cases and a deeper scope given that it is easier in conversation to engage in longer explorations of a person's educational biography. Written work is easier to scale and to include as assignments for all participants in vocational teacher training or apprenticeships, etc. What is not as flexible is the requirement that such cases be about unusual success or flourishing. This part of the research design is also what sets it apart from the mass of narrative methods used in teacher education on a wider scale (Kelchtermans, 2015; Moon, 2010; Tyson, 2016b). The point here is that it is not average or outright unwise practice that drives the development of vocational Bildung didactics or contributes most to reflection among practitioners but rather unusually wise practice. It is, as the case presented exemplifies, through vocational education curricula and practices that deviate from the expected in a positive way that the self-reflective capacity of the human being comes into its own. Such examples can become part of a feedback loop through which the development of practice is driven more energetically towards richer Bildung-affordances. It is also through such cases that the conceptual matrix described by Kutscha (2008) of work and vocation, Bildung and culture is potentially enriched and expanded upon the most. This is more of a logical conclusion than an empirical given that there are any number of examples of vocational education biographies which lack Bildung and culture or where these are only peripherally present. In this sense cases such as this are, following Flyvbjerg (2006) extreme and (in the best of circumstances) paradigmatic.

It is easy to wonder what makes a particular case unusually wise, in relation to what criteria and according to whom? I have found that this judgment can be left to the practitioners themselves when telling their stories. It is then left to the researcher/s to determine if a case narrative warrants inclusion and interpretation in published work. A single case is in this respect always misleading because it cannot provide any alternative points of view. This simply reiterates the above point in another way, a single researcher is in this respect always misleading because $\mathrm{s} /$ he can only approach the cases gathered through a particular constellation of perspectives (I do not want to give the impression that a person is only capable of one point of view). These caveats are applicable here as well.

Much more could be said also about the difference between accounts of enacted Bildung didactics as compared to experienced given that a teacher engaging in didactical action does not have direct access to the other person's experience of their interaction. On 
the other hand, when Mr. B. speaks about his teachers and what they afforded him through their didactical actions and curricula, it is not a given that they intended what he experienced.

Finally, when it comes to that part of method that is oriented towards analysis it depends largely on two issues. First, on the kind of case being developed (Tyson, 2016b) and second on how far the research has progressed relating to a particular field of vocational Bildung didactics. Regarding the latter it can be reasoned that as the number of relevant narratives grows it is possible to begin conducting comparative analyses of discourse, patterns, etc. that utilize methods and perspectives common in social science. Regarding the former, the case being developed here of expanding the conceptual basis for what it means to talk about general Bildung in a vocational context and of exploring a possible curriculum pattern immanent to the case, the method is philosophical. In other words it is about creating a coherent argument about general Bildung as understood by Humboldt and then to demonstrate variations of it inherent to the case by using his concepts of general and special Bildung (reformulated as expansive and intensive/exclusive).

\section{The case}

The case presented, parts of the educational biography of craftsman Wolfgang B., is unusual in that he is master of three crafts: bookbinding, gilding and engraving. This together with his extensive experience of teaching represents the formal reasons that the research design of the case being unusually rich is met. It consists of about $20 \mathrm{hrs}$ of recorded and transcribed conversations that were subsequently edited, removing those parts of the conversations that referred to other matters, digressed or were otherwise irrelevant, and published as a whole (Tyson, 2015a). In previous work, Tyson (2014) and Tyson (2015b) I have focused more on narrative episodes that Mr. B. remembered discussing aesthetic Bildung-experiences in the former and vocational ethics in the latter. In considering aesthetic Bildung as part of his educational biography I touched briefly on the present topic writing (Tyson, 2014, 352) that it presented examples of 'Bildung through expanding on the potentials for knowledge development in craft-related tasks and Bildung through vocational mastery. The former is possible with little practice whereas the latter occurs precisely as a result of practice.' The present discussion takes these indications further especially with regards to the larger curriculum pattern that is present in the case. I will begin with a brief summary of the vocational biography of Mr. B.

\subsection{The vocational biography of Wolfgang B.}

Wolfgang B. was born 1935 in Stuttgart and graduated upper secondary school with an Abitur in 1952 at age 17, granting him access to study at the university. However his father, a highly skilled craftsman at the TWS (Technical works Stuttgart) insisted he learn a trade first and so he ended up apprenticing as a bookbinder earning a journeyman's certificate both as hand- and industrial bookbinder. The basic structure was four days 
in the workshop and one day at vocational school each week but this was supplemented with elective evening and weekend courses. Halfway through the apprenticeship he also enrolled in a course that began preparing for a future master bookbinder exam. He was also suggested as a participant in Begabtenförderung (support for talented apprentices) to which I will return below. It is clear from this that he was able to make use of a wide variety of educational affordances beyond the mandatory apprenticeship training. It should be mentioned here that the events of WWII, where his father as a social democrat and engaged anti-nazi escaped deportation in large part due to his irreplaceable skill in connection with making submarines, play a central role in his childhood and youth. This is not the place to pursue those stories but it is worth bearing in mind that the apprenticeship of Mr. B. occurred during a time in post-war history when, as he says, 'people worked like ants'. Thus it can be assumed that some aspects of how his education was structured hinge on a significant number of people being prepared to work for the majority of their waking hours. After finishing the apprenticeship in 1956 he went for an initial 18 months to Stockholm, Sweden in order to reduce the time required between becoming a journeyman and taking the master's examination. However, he decided upon arrival to remain in Sweden and, after the 18 months were complete, he worked for some years at a large industrial bookbinding-firm. In the early 60 s he began a process of returning to craft-binding and for the better part of the decade spent much of his time in Paris at the Ecole Estienne, considered at the time one of the world's foremost colleges for education in bookbinding, gilding, engraving, case making, and other related arts and crafts. That is where he acquired his master-certificates as bookbinder, gilder and engraver. Following this, he worked for another decade or so as a prominent craftsman in Stockholm before gradually shifting towards work at a Steiner-school where he taught bookbinding for about 30 years before retiring and returning to his workshop. I met him as a student at the school and apprenticed with him after my own graduation 3

\subsection{Cases of general Bildung in Mr. B.'s vocational education narrative}

There are at least two clear-cut variations on general or expansive Bildung in Mr. B.'s narrative. The first is a vocational form of general Bildung in the sense of acquiring a broad expanse of knowledge about the world. The second is a uniquely vocational kind of Bildung, general vocational Bildung. Both of these are relevant to the matrix that Kutscha (2008) describes of work and vocation, Bildung and culture and to which I will return after the case presentation. A third kind of Bildung, the above mentioned Bildung through vocational mastery, which in Humboldt's terms would be the self-contradictory (because he excludes this kind of education from having any Bildung-value) Bildung through special or exclusive/intensive education, is not the theme here but receives some attention in Tyson (2014, 2015a). Briefly put, it encompasses Bildung-experiences

\footnotetext{
${ }^{3}$ I have discussed the problems and advantages of having such a close and long working relationship with Mr. B. elsewhere extensively (Tyson, 2015a). For the purposes of the inquiry, given its exploratory nature, the advantages outweighed the problems because it allowed for such an extended process of conversation.
} 
that are had through intense (manual) practice where emotional and volitional Bildung, ie. the development of eg. care, patience, endurance, etc. is at the forefront.

\subsection{Vocational general Bildung in the case}

Vocational general Bildung, mirroring traditional views on general Bildung and liberal education, is a recurrent theme in Mr. B.'s accounts. Two instances are especially clear. The first is a long narrative of how he received a rough iron cube for Christmas from his father together with some tools. This was taken from the metal-working apprentice-tasks where the aim was to make a perfect cube. Apart from descriptions of overcoming frustration, learning care, getting to know more and more about various tools and techniques, etc. Mr. B. also recalls his father repeatedly calling his attention to matters of general knowledge. Thus they speak about the cube as a platonic body and of the smiths at the Viking settlement at Hedeby. They also turn to the physics of solid bodies and their expansion and contraction relating to heat. These were all issues that connected with the process at hand but that in addition required a teacher proficient in the skills needed to make such a cube and in the various matters of general knowledge that could be brought into the context of making it. Interestingly, Stäudel (2010) has judged the same vocational task as being outdated and mostly a way for masters to exert control over the apprentices. This highlights the didactical character of such tasks and the pedagogical responsibility of the vocational teacher.

Another, similar, example is from the evening courses during the apprenticeship. These would stretch across perhaps a semester and it was possible to take part in a couple during the same time span where one might be two evenings per week, say Tuesday and Thursday, and the other might be on Friday, Saturday and Sunday. They often ran one after another on the same evening so that one course would go between 18.00 and 20.00 and the other would then run between 20.00 and 22.00. Not all apprentices availed themselves of these courses, Mr. B. explains that of the twenty or so apprentices who finished their apprenticeship in the same year as he did perhaps half of them were only sporadically partakers and a third not at all for various reasons. One of the elective evening courses was in edge-gilding (the gilding of the edges of book-leaves). His teacher there, called 'Lange-Otto' (Tall-Otto), insisted on not just teaching them the technique but also in taking them out into the woods to see the Hornbeam-trees from which some of the tools were made that he then proceeded to teach them how to make. Furthermore, as examples of what he would tell them, Mr. B. recounts discussions about gilding historically and what a gilded weather-cock meant on church-steeples. Again, none of these matters can be considered integral parts of learning a skill but rather are the effect of a teacher's pedagogical effort.

Wolfgang spoke of two other teachers from the evening/weekend courses $4^{4}$ Gollwitzer and Leinz. The former taught arts, including drawing (Kunsterziehung), every other Saturday and the latter technology, especially various press techniques such as intaglio/taille douce. Wolfgang recalled one of the tasks was to draw the braided pattern of a carpet beater. They made technical drawings, sketches, etc. as well. Another time Gollwitzer

\footnotetext{
${ }^{4}$ These two teachers were the topic of an additional hour-long conversation (06 July 2016) where the initial question was simply to confirm if the other teachers at the elective courses worked similarly to Lange-Otto. Not only was this affirmed, it resulted in the case expanding somewhat.
} 
brought a sack of potatoes, Wolfgang recalls:

Compare that with today when we have such abundance. He arrives one day with a sack of potatoes and a box of knives and colors and says: 'Kartoffeldruck meine Herren!' (Gentlemen! Potato prints!) And you get a potato and at the time not everyone was especially well fed and it upset me so when I came home I spoke with my father who said: typical academics, the stupidity, I'm sure he wasn't thinking that several of you probably sat there weeping over having to cut the potato instead of eating it. I told him I saw Steidle put two of them in his pockets immediately. But I can't explain the sense of reverence that descended upon us [as we began working]. And then he told us about the relationship between starch, pigment, paper and fixative, etc. And after half the potato was gone he brought out a picture of a mosaic from Ravenna that was so damn beautiful and then he told us that those who had the energy could stay and copy, the workshop is open for another three hours and then he left. And the next time he came to us and said: Well? Who has made what?

Returning to this experience later in the same conversation Mr. B. reflects that he is sure in retrospect that Gollwitzer knew exactly what he was doing, that introducing them to the potato prints wasn't an act that showed lack of empathy but a kind of test.

They were also invited to hear lectures at the Höhere Graphische Fachschule (perhaps best translated as The Vocational College of Graphic Arts). There was one in Stuttgart and one in Ulm that they visited. As examples of what they would learn there he mentions a series of two or three lectures on color and a time when there was a lesson on gold foil for prints where both users and manufacturers were invited to give presentations. Finally, the apprenticeships were embedded in the cultural life of Stuttgart at the time and they were expected to play an instrument as well as take dancing lessons. Together with their teachers at the vocational school they also made excursions; they visited monasteries like Eberbach and Maulbronn as well as libraries and other places. During these, they would learn about architecture, history and art. This kind of general Bildung in vocational education has certainly been argued for on a conceptual, philosophical level as mentioned in the introduction but it is a different matter to find out how such ideas have been enacted and experienced. I will call this general or expansive Bildung in VET. Having established the basic pattern, it seems possible to conduct larger studies with apprentices subjected to the same or similar tasks and curricula in order to determine how, when and how frequently certain tasks afford Bildung-experiences. Perhaps it will become evident that some are richer in such affordances, or that it is foremost the pedagogy of the master as teacher that matters, etc. The other direction possible to take is that each case of Bildung in relation to a vocational task represents a didactical example that vocational teachers can add to their repertoire (as argued in Tyson, 2016a).

\subsection{General or expansive vocational Bildung in the case}

The second kind of vocational general Bildung that Wolfgang speaks of is less commonly heard of in terms of Bildung. There are three instances in the case where he comes to speak of a general craft-vocational education. First, in describing his youth and growing 
up in a context of industrial and artisanal craftwork. Thus his father, as mentioned, was a highly skilled worker at the TWS and his uncle was a sculptor. Another uncle with whom he was evacuated for a large part of the war was a skilled farmer. His friends had parents who were, respectively, baker, technical foreman at Blohm und Foss (a company working with shipbuilding, turbine construction and other things), civil engineer and something to do with metal, perhaps casting. The civil engineer was owner of a group of workshops that made models for other larger companies such as Mercedes and Audi and they were always welcome to make use of the potentials that these afforded. He and his best friends through these and other acquaintances thus received an extensive craft-vocational education owing to their social and cultural context.

Second, early on in his apprenticeship Mr. B. was invited to participate in what was called Begabtenförderung, ie. support for talented students (which continues to this day in various forms in Germany). The formalities surrounding it were unclear to him but in practice it meant that for about three months each year he would take part in various educational activities. These three months were not all at once, but parsed out. Sometimes they were interned at the Akademie Comburg (which still exists albeit devoted to other educational activities) for up to a month, at other times they met for shorter periods. Part of this took place on their holidays so of those three months per year not all of it came at the expense of time spent in the workshop and at the vocational school. During these months Mr. B. together with 50-100 other apprentices from various vocations did a number of things. At the courses they would often hear presentations of different vocations, presentations that included a lot of practical demonstrations. He remembers a gunsmith and gun engraver presenting their crafts as well as a miller who came and spoke to them at length about making grind stones. As he recalls, the gun-engraver was the initial inspiration for what later became his training in stampengraving. There was also a lot of general education in mathematics, geometry, physical education, questions about health and safety at work, etc. This included cultural studies where Mr. B. remembers one particular man who spoke to them about Reuchlin (14551522) the early German humanist who, among other things, wrote a Hebrew grammar as well as a book on the Kabbalah. They would go for excursions in the local geography, visiting a number of dripstone caves and archeological digs by the Boden Sea and in the Lohnetal. During these excursions they would learn about geography, geology, history, etc. Finally, they also made a lot of visits to various firms such as Göppinger Kaliko (makers of artificial leather and bookbinding cloth), Zerkall (paper mill), Mercedes and Bölkow (aircraft manufacturer). All of these things make this an example of general Bildung in VET as well as something beyond that. Taken together these experiences were an important part of Mr. B.'s apprenticeship giving him a view of, and feel for, the richness and variety of human culture and technical knowing.

Third, his gilding teacher at the Ecole Estienne, Raymond Mondange, would sometimes send his students, they were about 15 , to visit various craftsmen around Paris and to see their workshops (further described in Tyson, 2015b). One was a builder of camera cases in wood for, among other things, aerial photography, one was a case-maker and another an ivory-carver. Through these visits he received a further deepening of his understanding of various crafts and how craftwork that on a superficial level seems to 
have nothing in common with gilding and bookbinding can inspire new ways of dealing with problems arising in ones own work. These visits also gave rise to questions that led Mr. B. and his colleagues to visit museums and to concern themselves with the history of various arts thus again contributing to general Bildung in VET as well. For instance, they were sent to the ivory carver because they played chess during breaks with pieces carved of ivory. Upon hearing about Wolfgang's Swedish connection the carver spoke about narwhales and the belief in earlier times that their horn was from a unicorn. He then directed them to a museum where they would find a relevant tapestry and some carvings of exceptional quality. Mondange would also appear to give brief lectures, in connection with the ivory carver on the Roman pugillaria, pieces of wood or ivory that were covered on one side with wax to allow for notes to be written and erased by senators. These are considered by some the predecessors of the so-called codex book form upon which European bookbinding is based. This resulted in them visiting libraries where pugillaria could still be found incorporated into the covers of old books. Compared to the formal curriculum of the vocational school and Begabtenförderung, Mondange had more of an informal one based on his ability to expand upon the implicit potential of what his students were engaged in. Such informal curricula are equally important to document however, given that they can contain valuable suggestions for others in creating more formal ones or for the didactical practice of other teachers. Mondange's insistence upon sending his students to various craftspeople was also grounded in an explicit ethical view related to the development of interest beyond one's limited field of practice, the development of a sense of professional fraternity (confrére as he called it) among practitioners (this aspect is discussed at length in Tyson, 2015b).

Throughout his educational biography then, next to general Bildung in VET, there is a strong presence of what I will call vocational general Bildung in the sense of a wide-ranging practical survey of craft-work. Of course, any good training will have job rotation and a general look at what other's in related fields are doing but the extent to which this was an overt pedagogical activity on the part of Mr. B.'s teachers is what is relevant here. First, because it suggests a curriculum-pattern that is perhaps particular to vocational schools and not easily available in strictly on the job training. Second, because it suggests a field of empirical research, vocational general Bildung articulated in highly skilled teacher-practitioner biographies, that has the potential to provide enriching perspectives on how to create curricula for VET, not just in crafts but just as well in eg. engineering, medicine or agriculture. But this brings me to the part summarizing and discussing the case as it relates to my revision of Humboldt.

\section{What would Humboldt say?}

The case describes curricula and pedagogies that are within the scope of Humboldt's concept of general Bildung understood as expansive Bildung. The stories of the cube, learning edge-gilding and potato printing in the way the teachers made a point of going beyond the purely manual aspects to include cultural, historical and scientific contexts within which the action takes place. Begabtenförderung and the impulse that Mondange 
gave his students through an occupational broadening of the horizon in the sense that they provided the students with an understanding of other occupations, of their tools, practices and materials. Clearly the case does not prove that an expansionist curriculum in vocational education is better than an exclusive one, that would require other means of research. It does question the traditional divide between generalist and specialist and suggests curriculum patterns for those who find an expansive form of VET worthwhile. It remains an open question if a curriculum aiming at vocational Bildung is best thought of as a continuously narrowing one with increasing specialization or rather as an oscillating movement between intensification and expansion. I suspect that depends somewhat on vocational context.

A clear pattern in the educational biography is the importance of vocational schools and a vocational pedagogy on the part of the teachers. Of course, there is the potential for vocational Bildung through a self-directed learning through work but a series of didactical vocational Bildung-affordances constructed at the upper secondary or postupper secondary level can perhaps increase innovation and the effectiveness with which individuals feel emboldened to trust their capacity to direct their further vocational training.

The above considerations support an explicit inclusion of vocational Bildung, discussed here in terms of general Bildung in VET and vocational general Bildung in VET curricula and understand it as a way of connecting 'work and vocation, Bildung and culture' that enriches vocational practice. Empirical research is needed both to show ways in which this has been done (that it is not just theory) and to allow for systematic work relating to how this could be done going forward. Perhaps the case presented here of Wolfgang B. and his vocational education is not the best and most relevant template for developing new VET curricula that place an emphasis on vocational Bildung, in the above senses and in the sense explored elsewhere of aesthetic Bildung (Tyson, 2014) and vocational ethics (Tyson, 2015b). It does, however, show the potential inherent in this kind of empirical approach.

The case can also be understood as a paradigmatic (Flyvbjerg, 2006) example of Kutscha's matrix as it can appear in a vocational field (that of crafts). Such matrixes then, are not just theoretical constructs but can be found in the biographical trajectories of people's lives. They may be unusual and idiosyncratic but it is in these outliers that the strongest empirical explorations are possible of where vocational education as a special or exclusive kind of training is reversed into something general or Allgemeinmenschlich. Although not everyone will be a craftsperson and experience the general through that particularity it is possible to take a similar path toward the general from other fields of vocationalism. It makes sense here to turn the tables somewhat on Humboldt and suggest that he has approached the matter from the vocationalism, the matrix of work and vocation, Bildung and culture, specific to a classical scholar. What Humboldt would say to all of this is something I leave to the readers' historical imagination. 


\section{Concluding thoughts}

To summarize, the argument has been that empirical case studies of vocational education biographies rich in Bildung-experiences can expand on vocational Bildung theory and contribute to curriculum development. The main contribution of this study is as a pilot case exploring a line of inquiry in connection with general Bildung in VET and the matrix of vocationalism described by Kutscha (2008) as work and vocation, Bildung and culture. The results suggest that there are rich fields of systematic inquiry to be explored relating to the two patterns or categories of general Bildung in VET and vocational general Bildung and the empirical variations that can be found within and across vocational fields. Running through these two patterns are several differing interpretations of the case, predominantly:

1. As a narrative of practice that is relevant to other practitioners as they enrich what practitioners can imagine doing themselves in enacting vocational Bildungaffordances systematically through curricula and teaching practice $5^{5}$

2. As an articulation of vocational Bildung didactics that, given other, related, narrative cases can be analyzed by scholars in order to increase understanding of vocationalism as it relates to biographical development, lifelong learning, vocational pedagogy and other relevant perspectives of inquiry.

3. As a contribution to the argument for why vocationalism not only in theory but also in practice is an important part of VET.

Finally, even if developments in the world of work would one day make vocations antiquated and even if this coincides with a situation where few need to work at all in order to earn a living, the issue still remains what kind of education one needs in order to do work in a personally meaningful way. Thus with a larger number of similar educational biographical studies it can become possible to discern general patterns regarding vocational Bildung which can contribute to the creation of curricula in which the specific vocations taught is less important than is the vocationalism and general vocational Bildung that can be achieved through them. For instance, perhaps learning a craft similarly to how Mr. B. has described his education holds relevance today, not because it opens the door to employment in bookbinding but because the vocational Bildung achieved through it is relevant across a much wider expanse of work and in the personal unfolding of a lifelong capacity and interest in learning.

\footnotetext{
${ }^{5}$ This raises a further issue regarding the relationship between practice and practical knowledge something that I have explored further in an article submitted for publication with the title What is excellence in practice? Empirical explorations of vocational Bildung and practical wisdom through case narratives.
} 


\section{References}

Arendt, H. (1989). Vita activa oder Vom tätigen Leben. München: Piper.

Biesta, G. (2002). How general can Bildung be? Reflections on the future of a modern educational ideal. Journal of Philosophy of Education, 36(3), 377-390.

Brater, M., Buechele, U., Fucke, E., \& Herz, G. (Eds.) (1988). Berufsbildung und Persönlichkeitsentwicklung. Stuttgart: Verlag Freies Geistesleben.

Crawford, M. (2009). The case for working with your hands. New York: Penguin.

Dormer, P. (1994). The art of the maker. London: Thames and Hudson.

Flyvbjerg, B., Landmann, T., \& Schram, S. (2012). Real social science. Applied phronesis. Cambridge: Cambridge University Press.

Flyvbjerg, B. (2006). Five misunderstandings about case-study research. Qualitative Inquiry, 12(2), 219-45.

Flyvbjerg, B. (2001). Making social science matter. Cambridge: Cambridge University Press.

Frayling, C. (2011). On craftsmanship. London: Oberon Books.

Gessler, M., \& Howe, F. (2015). From the Reality of Work to Grounded Work-Based Learning in German Vocational Education and Training: Background, Concept and Tools. International Journal for Research in Vocational Education and Training (IJRVET), 2(2), 214-238.

Gonon, P. (2009). The Quest for Modern Vocational Education: George Kerschensteiner Between Dewey, Weber and Simmel. Frankfurt: Peter Lang.

Gonon, P. (2002). Georg Kerschensteiner: Begriff der Arbeitsschule. Darmstadt: Wissenschaftliche Buchgesellschaft.

Gruschka, A. (2011). Zur Unverzichtbarkeit der 'Bildung im Medium des Berufs' - eine Replik zu Günther Kutscha. Pädagogische Korrespondenz, 43, 84-90.

Hammershøj, L.G. (2009). Creativity as a question of Bildung. Journal of Philosophy of Education, 43(4), 545-558.

Hinchliffe, G. (2004). Work and human flourishing. Educational Philosophy and Theory, $36(5), 535-547$.

Humboldt, W.v. (1984). Schriften zur Anthropologie und Bildungslehre. Klett-Cotta: Frankfurt.

Kelchtermanns, G. (2015). Learning from 'good examples of practice'. Teachers and Teaching: Theory and practice, 21(4), 361-365.

Kerschensteiner, G. (1904). Berufs- oder Allgemeinbildung. Paderborn: Schningh.

Kutscha, G. (2008). Beruflichkeit als regulatives Prinzip flexibler Kompetenzentwicklung These aus berufsbildungstheoretischer Sicht. Berufs- und Wirtschaftspädagogik online, Bwp@, 14.

Kutscha, G. (2003). Zum Verhältnis von allgemeiner und beruflicher Bildung im Kontext bildungstheoretischer Reformkonzepte. Rückblick und Perspektiven. Zeitschrift für Berufs- und Wirtschaftspädagogik, 3, 328-349.

Lange, U., Harney, L., Rahn, S., \& Stachowski, H. (Eds.) (2001). Studienbuch Theorien der beruflichen Bildung. Bad Heilbrunn: Klinkhardt. 
Laszlo, C., Brown, J.S., Sherman, D., Barros, I., Boland, B., \& Ehrenfeld, J. (2012). Flourishing, a vision for business and the world. Journal of Corporate Citizenship, $46,31-51$.

Lüth, C. (1998). On Wilhelm von Humboldt's theory of Bildung. Dedicated to Wolfgang Klafki for his 70th birthday. Journal of Curriculum Studies, 30(1), 43-59.

Løvlie, L. (2002). The promise of Bildung. Journal of Philosophy of Education, 36(3), 467-486.

Løvlie, L., \& Standish, P. (2002). Introduction: Bildung and the idea of a liberal education. Journal of Philosophy of Education, 36(3), 317-340.

Masschelein, J., \& Ricken, N. (2003). Do we (still) need the concept of Bildung? Educational Philosophy and Theory, 35(2), 139-154.

Moon, J. (2010). Using story in higher education and professional development. New York: Routledge.

Nordenbo, S.E. (2002). Bildung and the thinking of Bildung. Journal of Philosophy of Education, 36(3), 341-352.

Obermann, A. (2013). Im Beruf Leben finden. Allgemeine Bildung in der Berufsbildung didaktische Leitlinien für einen intergrativen Bildungsbegriff im Berufsschulunterricht. Göttingen: V \& R Unipress.

Plato (2008). Laws, translated by Benjamin Jowett. Project Gutenberg, ebook \#1750.

Platon (2008). Lagarna, översatta av Jan Stolpe. Stockholm: Atlantis.

Rauner, F., \& Bremer, R. (2004). Bildung im Medium beruflicher Arbeitsprocesse, Zeitschrift für Pädagogik, 50(2), 149-161.

Reutter, G. (2004). Thesen zur (Un-)Gleichwertigkeit von allgemeiner und beruflicher Bildung/Weiterbildung. Deutsches Institut für Erwachsenenbildung. http://www.diebonn.de/esprid/dokumente/doc-2004/reutter04_03.pdf.

Accessed 7 July 2016.

Rittelmeyer, C. (2012). Bildung, ein pädagogischer Grundbegriff. Stuttgart: Kohlhammer.

Rist, G., \& Schneider, P. (1979). Integrating vocational and general education: a Rudolf Steiner school. Hamburg: Unesco Institute for Education.

Schön, D. (1987). Educating the reflective practitioner. San Francisco: Jossey-Bass Publishers.

Schön, D. (1983). The reflective practitioner. New York: Basic Books.

Sennett, R. (2008). The craftsman. London: Allen Lane, Penguin Books.

Stäudel, L. (2010). Kompetenzorientiert unterrichten: Aufgaben gestalten, Ethik \& Unterricht, No. 1.

Thompson, C. (2005). The non-transparency of the self and the ethical value of Bildung. Journal of Philosophy of Education, 39(3), 519-533.

Tyson, R. (2016a). Pedagogical imagination and practical wisdom: The role of successnarratives in teacher education and professional development. Reflective Practice, $17(4), 456-471$.

Tyson, R. (2016b). The didactics of vocational Bildung: How stories matter in VET research. Journal of Vocational Education and Training, 68(3), 359-377. 
Tyson, R. (2016c). When expectations clash: Vocational education at the intersection of workplace and school. Interchange, 47(1), 51-63.

Tyson, R. (2015a). Vocational Bildung in action. Licentiate thesis, University of Stockholm, Department of Education.

Tyson, R. (2015b). Educating for vocational excellence: the auto/biographical exploration of enacted craft pedagogy. Vocations and Learning, 8(2), 229-245.

Tyson, R. (2014). Aesthetic Bildung in vocational education: the biographical case of bookbinding master Wolfgang B. and his apprenticeship. Vocations and Learning, $7(3), 345-364$.

Uljens, M. (2004). Didaktik: teori, reflektion och praktik. Lund: Studentlitteratur.

Volanen, M.V. (2012). Theoria, praxis, poiesis. Dissertation, University of Jyväskylä.

Westbury, I., Hopmann, S., \& Riquarts, K. (Eds.) (2000). Teaching as a reflective practice. The German didaktik tradition. London: Lawrence Erlbaum Associates.

Winch, C. (2012). Dimensions of expertise: a conceptual exploration of vocational knowledge. London: Continuum.

With, A. (1994). A reconstituted general education: the integration of the vocational and the liberal. Journal of Curriculum Studies, 26(6), 593-600. 


\section{Bibliographical notes}

Ruhi Tyson is a Ph.D. student at Stockholm University, Department of Education. His research interests include Bildung as a part of vocational education, biographical studies and development of teacher education curricula to include more focus on practical knowledge.

\section{Acknowledgement}

I am grateful for the helpful comments of the two anonymous reviewers, they were instrumental in improving the article. 